\title{
Belirsizlik ve Tedarik Zinciri Riski: Risk Azaltımında Tedarik Zinciri Esnekliğinin Aracı Rolü
}

\section{Dilşad GÜZEL ${ }^{1}$ Gülşah KORKMAZ}

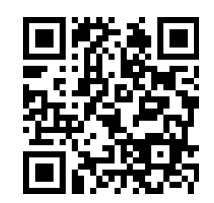

\begin{tabular}{ccc}
\hline $\begin{array}{c}\text { Geliş Tarihi/ Received } \\
08 / 04 / 2020\end{array}$ & Kabul Tarihi/ Accepted & Yayın Tarihi/ Published \\
26/05/2020 & $15 / 07 / 2020$ \\
\hline Citation/Atıf: Güzel, D. ve Korkmaz, G., (2020), Belirsizlik ve Tedarik Zinciri Riski: Risk \\
Azaltımında Tedarik Zinciri Esnekliğinin Aract Rolü, Atatürk Üniversitesi Iktisadi ve Idari \\
Bilimler Dergisi, 34(3): 1045-1064, DOI: $10.16951 /$ atauniiibd.716449 \\
\hline
\end{tabular}

Öz: Günümüz piyasalarında artan rekabetle baş edebilmek için, işletmeler çeşitli stratejiler geliştirmektedir. Bu yoğun rekabet ortamı aynı zamanda tedarik zincirinde yüksek belirsizlik yaratabilmektedir. Yüksek çevresel belirsizlikle karşı karşıya olan işletmeler tedarikte aksamaların meydana gelmesi, üretim ve teslimatta gecikmelerin yaşanması gibi risklerle karşılaşmaktadır. $\mathrm{Bu}$ çalışma, işletmelerin karşı karşıya kaldıkları tedarik zinciri risklerinin önceliklerini ve bu risklerin hangi koşullarda hafifletilebileceğini anlamayı amaçlamaktadır. Çalışma kapsamında, çevresel belirsizlik ve tedarik zinciri riski ve tedarik zinciri riskinde tedarik zinciri esnekliğinin aracı rolü iki ana başlık altında ele alınmıştır. Çalışma, Erzurum ilinde faaliyet gösteren üretim işletmeleri üzerinde yapılmıştır. Veri toplama metodu olarak anket yöntemi kullanılmıştır. Erzurum üretim işletmelerine uygulanan 87 adet anket formu değerlendirmeye tabi tutulmuştur. Verilerin analizinde SPSS 23 programı kullanılmış ve Tek Yönlü Varyans analizi, Regresyon analizi ve Sobel $\mathrm{z}$ testi uygulanmıştır. Yapılan analizler sonucunda çevresel belirsizliğin tedarik riski ve dağıtım riski üzerinde etkiye sahip olduğu görülürken çevresel belirsizliğin üretim süreci riski üzerinde etkisinin olmadığı görülmektedir. Ayrıca tedarik esnekliği, dağıtım esnekliği ve üretim esnekliğinin tedarik zinciri riskleri ve çevresel belirsizlik arasındaki ilişkide etkisinin olmadığı sonucuna da ulaşılmaktadır.

Anahtar Kelimeler: Çevresel Belirsizlik, Tedarik Esnekliği, Dağıtım Esnekliği, Üretim Esnekliği, Tedarik Riski

Uncertainty and Supply Chain Risk: The Role of Supply Chain Flexibility in Risk Reduction

Abstract: In order to cope with increasing competition in today's markets, businesses develop various strategies. This intense competition environment can also create high uncertainty in the supply chain. Businesses facing high environmental uncertainty face risks such as disruptions in supply, delays in production and delivery. This study aims to understand the priorities of the supply chain risks that enterprises face and the conditions under which these risks can be mitigated. Within the scope of the study, the role of supply chain elasticity in environmental uncertainty and supply chain risk and supply chain flexibility is discussed under two main headings. The study was carried out on production enterprises operating in Erzurum

${ }^{I}$ Doç.Dr., Atatürk Üniversitesi İktisadi ve İdari Bilimler Fakültesi İşletme Bölümü, Üretim Yönetimi ve Pazarlama ABD, https://orcid.org/0000-0003-1421-7692

${ }^{2}$ Doktora Öğrencisi, Atatürk Üniversitesi Sosyal Bilimler Enstitüsü İsletme Anabilim Dal, https://orcid.org/0000-0002-3909-2745 

Rolü

province. Questionnaire method was used as data collection method. 87 questionnaire forms applied to production facilities in Erzurum were evaluated. SPSS 23 program was used in the analysis of the data and One-Way Variance Analysis (ANOVA), Regression analysis and Sobel z test were used. As a result of the analysis, it is seen that environmental uncertainty has an effect on supply risk and distribution risk, while environmental uncertainty has no effect on production process risk. It is also concluded that supply flexibility, distribution flexibility and production flexibility have no effect on the relationship between supply chain risks and environmental uncertainty.

Keywords: Environmental Uncertainty, Supply Flexibility, Distribution Flexibility, Production Flexibility, Supply Risk

\section{Purpose of the Study}

\section{EXTENDED SUMMARY}

The purpose of this research is to understand the priorities of the supply chain operational risk faced by businesses and under what conditions these risks can be mitigated. For this purpose, the mediating role of supply chain flexibility in environmental uncertainty and supply chain risk is investigated.

\section{Research Question}

What are the supply chain operational risks faced by businesses?

Under which conditions can operational chain operational risks be mitigated?

What is the mediating role of supply chain flexibility in environmental uncertainty and supply chain risk?

\section{Literature Review}

As a result of the literature review on supply chain risk and environmental uncertainty, the scale and research model in Sreedevi and Saranga (2017) "Uncertainty And Supply Chain Risk: The Moderating Role Of Supply Chain Flexibility In Risk Mitigation" were used in the study.

In Sreedevi and Saranga (2017), which investigated the mediating role of supply chain flexibility in the relationship between environmental uncertainty and supply risk, it was concluded that supply flexibility and production flexibility had a mediating effect in this relationship, but distribution flexibility did not have any effect. In our study, it was concluded that supply flexibility, production flexibility and distribution flexibility do not have an intermediary effect between environmental uncertainty and supply chain.

\section{Methodology}

Questionnaire method was chosen as the data collection method. production companies operating in Erzurum are the main population of the research. In this sense, 87 questionnaire forms were evaluated.

The questionnaire form used in the research consists of 32 questions. Of the 25 questions related to the variables in the research model, 6 are environmental uncertainty, 8 are supply chain flexibility, 6 are supply chain risk, 3 are competition intensity, and 2 are questions related to perceptions of preventive risk reduction. Apart from the research model, 6 questions asked to determine the demographic characteristics of the respondents. 
In the research, SPSS 23 program was used to investigate the mediating role of supply chain flexibility in environmental uncertainty and supply chain risk, Variance analysis, Regression analysis and Sobel z test were performed.

\section{Results and Conclusions}

As a result of the research, it is seen that 2 of the 6 hypotheses created for the research conducted for the production enterprises operating in Erzurum were accepted and 4 were rejected.

When the model is examined in line with the results of the research, it is seen that environmental uncertainty has an effect on supply risk and distribution risk, while environmental uncertainty does not have an effect on production process risk. It is also concluded that supply flexibility, distribution flexibility and production flexibility have no effect on the relationship between supply chain risks and environmental uncertainty.

Enterprises participating in the research should take measures such as determining strategies to minimize their exposure to supply and distribution risks in case of environmental uncertainty, maintaining security stocks against supply risk, and ensuring efficient supply chain risk management. In addition, in order to minimize distribution risks, they should focus on reducing supply risk by predicting environmental uncertainty conditions.

\section{Giriș}

Üretimin hızlı bir şekilde gelişimi ve bu doğrultuda üretim araçlarının çeşitlenmesi ile birlikte bu gelişim ve çeşitlenmenin olumsuz etkilerini de günlük yaşantımız içerisinde yerini almıştır (Erciş, vd., 2019:943). Günümüz piyasalarında arz ve talebin hızla artması ve sürekli olarak değişkenlik göstermesi tedarik zincirlerini daha karmaşık bir hale getirmekte ve dolayısıyla işletmeler arasındaki yoğun rekabet artık tedarik zincirleri arasında da yaşanmaktadır. Küresel anlamda ticaretin öneminin artmasına paralel olarak ortaya çıkabilecek riskler ve belirsizliklerin tedarik zinciri akışının bir parçası haline geldiği görülmektedir. Piyasalarda meydana gelen bazı gelişme ve trendler çeşitli risklerin ortaya çıkmasına neden olmakta, mevcut risklerin etki ve olasıllğııı artırmakta ve bunun sonucunda tedarik zincirlerinin kırılganlığının artmasina neden olmaktadır (Erdal, 2017).

Tedarik zinciri üzerinde ortaya çıan riskler finansal, performans, fiziksel, psikolojik, sosyal ve zamansal anlamda kayıplara yol açabileceğinden işletmeler ve organizasyonların karar alma süreçlerinde ortaya çıkabilecek risk ve belirsizlikleri daha dikkatle incelemeleri ve gerekli önlemleri almaları gerekmektedir (Kara \& Firat, 2015). Tedarik zinciri riskleri; uzun teslimat süreleri, stoklar, müşteri talebini karşılamada yetersizlik ve üretim maliyetlerinde artış gibi birçok soruna yol açabilmektedir (Mital vd., 2018).

İşletmelerin rekabet ortamında maksimum karlılık ya da minimum maliyet anlamında başarı sağlayabilmeleri bakımından öncelikle yeniliklere açık ve esnek olmaları küreselleşen dünyada kendilerinden söz ettirmelerini, 

Rolü

rakiplerine karşı üstünlük sağlayabilmelerini ve büyük pazarlarda yer almalarını kolaylaştırmaktadır (Güzel \& Demirdöğen, 2016). Tedarik zincirlerinin başarılı bir şekilde yönetilebilmesi ve amaçlarına ulaşabilmesi için öncelikle; düşük maliyet, kalite arttırıcı çalışmalar, globalleşme ve bu sürecin gerekliliklerine uyum, işletmeler arası ilişkilerdeki gelişmişlik düzeyi, çevresel koşulların doğasındaki belirsizliğin azaltılmasına yönelik çalışmalar, müşteri memnuniyet düzeylerini arttırmaya yönelik faaliyetler, etkin bilgi sistem teknolojilerinin kullanımı ve esneklik koşulları gelmektedir (Vatansever, 2010).

Tedarik zincirleri, rekabet edebilmek ve değişen pazar koşullarına gerekli uyumu sağlayabilmek için esnek olmak zorundadırlar. Burada söz konusu olan esnekliğin yalnızca tek bir işletme açısından sağlanması yeterli olmayacaktır. Çünkü bir sistemin gücü ancak en zayıf bileşeninin gücü ile tanımlanabilir. Bu nedenle tedarik zinciri sisteminin geneline yönelik olarak "tedarik zinciri esnekliğinin" sağlanmaya çalışılması gerekmektedir (Topoyan, 2011).

Günümüz tedarik zincirleri çok sayıda bağlantı içerdiğinden bu durum onları belirsiz faktörlerin etkilerine karşı savunmasız kılmaktadır. Böyle bir ortamda işletmelerin başarısızlık olasılığının yüksek olduğu görülmektedir. Dolayısı ile bu başarısızlıktan ve tedarik zincirine zarar veren durumlardan kaçınmak adına acil durum planlarının hazır bulundurulması gerekmektedir (Oliveira vd., 2017). Bu çalışmada belirsizlik ve risk durumlarında riski azaltmaya yönelik tedarik zinciri esnekliğinin aracı rolünün etkisi araştırılmıştır. Çalışmanın amacı, işletmelerin karşı karşıya kaldıkları tedarik zinciri operasyonel riskinin önceliklerini ve bu risklerin hangi koşullarda hafifletilebileceğini anlamaktır. Çalışmada çevresel belirsizlik, tedarik zinciri riski, tedarik zinciri riskinde tedarik zinciri esnekliğinin aracı rolü kısaca açıklanmış ve sunulan hipotezler test edilmiştir.

\section{2. Çevresel Belirsizlik ve Tedarik Zinciri Riski}

Çevresel belirsizlik; işletmeler üzerinde etkisi olan olayların kaynaklarının ve buna bağlı olarak ortaya çıkan firsatlar ve tehditlere yönelik değişimlerin öngörülememesi şeklinde tanımlanmaktadır (Çetindaş \& Çelik, 2017). Çevresel belirsizlik işletmeleri çevreleyen ortama ilişkin bilgi eksikliğinden kaynaklanmaktadır (Estevez vd., 2010).

Çevresel belirsizlik çok boyutludur ve işletmeler s1k s1k çevresel belirsizlikle karşı karşıya kalmaktadır. Çevresel belirsizliğe ilişkin başlıca kaynaklar müşteriler, tedarikçiler, teknoloji ve rakipler olmakla birlikte, daha önceki çalışmalarda talep, üretim süreci, arz ve kontrol belirsizliği gibi çeşitli belirsizlik kaynakları tespit edilmiştir. Tedarik zincirlerinde çevresel belirsizlik düzeyinin yüksek olması kuruluşların ortaklık kalitesini ve tedarik zinciri performansını etkilemektedir (Jangga vd., 2015). Ayrıca yüksek düzeydeki çevresel belirsizlik, ortaklar arasında firsatçı davranış riskleri gibi çeşitli tedarik zinciri risklerinin artmasına sebep olabilmektedir (Srinivasan vd., 2011). 
Talep belirsizliği tedarik zinciri belirsizliklerinin başlıca kaynaklarından biri olmakla birlikte üretim ve tedarik belirsizliği gibi birçok belirsizlik kaynağı da bulunmaktadır (Ho vd., 2005).

Tedarik zinciri riski, tedarik zincirinin etkin yönetimi üzerinde etkileyen ve bunun sonucu olarak karıșıklığa neden olan bir olaya maruz kalınması şeklinde tanımlanmaktadır (Oliveira vd., 2017). Tedarik zinciri riskleri tedarik zincirinde çeşitli problemler yaratmakta ve bu da kesintiler veya gecikmeler nedeniyle akışta beklenmeyen değişikliklere neden olmaktadır. Bu aksamalar kısa vadeli veya uzun vadeli olabilmekte ve kuruluşlar için büyük tehditler oluşturabilmektedirler. Tedarik zinciri riskleri, nihai müşteriye hizmet vermek için tedarik zinciri verimliliğini tehlikeye atmaktadır (Mital vd., 2018).

Tedarik zinciri risklerinin etkileri beklenenin aksine sadece cari finansal kayıplar olarak karşımıza çıkmamaktadır. Kısa ve uzun vadede tedarik zinciri kesintileri, ürün kalitesinin düşmesi, malzeme, teçhizat ve ürünün zarar görmesi, itibar kaybı, teslimat aksamaları vb. olarak da karşımıza çıkabilmektedir. Tüm tedarik zinciri fonksiyonlarının etkin ve verimli bir şekilde uygulandığı tedarik zincirleri bile savaş, çatışma, terörizm gibi jeopolitik olaylar, doğal afetler ve salgın hastalıklar gibi risklerden etkilenebilmektedir (Erdal, 2017).

Tedarik zinciri riskleri genellikle tahmin edilemez olduğundan ve kuruluşlar için büyük zararlar oluşturduğundan bu risklerin kuruluş çapinda anlaşılması ve riski azaltmaya yönelik yaklaşımların benimsenmesi gerekmektedir. Yapılan literatür araştırmalarında tedarik (arz) riski, dağıtım riski ve üretim süreci riski gibi çeşitli tedarik zinciri risklerinin olduğu görülmektedir (Chopra \& Sodhi, 2004). Tedarik riski, malların arzında meydana gelen zaman, kalite ve miktar açısından akışta kusurlu siparişlerle sonuçlanan muhtemel başarısızlık şeklinde tanımlanmaktadır. Üretim süreci riski, malların doğru zamanda istenen kalite ve miktarda üretilmemesi olarak tanımlanmaktadır (Kumar vd., 2010). Dağıtım riski ise, kalite ve güvenilirlik açıssından doğru ürünün doğru zamanda teslim edilememesine yönelik ortaya çıkan risk şeklinde tanımlanmaktadır (Sreedevi \& Saranga, 2017).

Bir siparişin hacmindeki veya tüketici gereksinimlerindeki belirsizlik arttıkça tedarikçilerin zamanında ve uygun kalitede teslimat yapma yeteneği azalmaktadır. Ayrıca kısa yaşam döngülerine sahip ürünlerin piyasa talebindeki belirsizlik, talep tahminlerinin ve ilgili envanter seviyelerinin doğruluğunu etkilemektedir. Dolayısıyla talep, üretim ve tedarik ortamlarındaki belirsizlik, doğru ürünü doğru zamanda teslim etme açısından teslimat kalitesini ve güvenilirliğini etkileme potansiyeline sahiptir. $\mathrm{Bu}$ nedenle son derece belirsiz ortamlarda faaliyet gösteren işletmeler teslimat başarısızlıklarına karşı daha savunmasız olmaktadırlar (Sreedevi \& Saranga, 2017). 

Rolü

\section{Tedarik Zinciri Riskinde Tedarik Zinciri Esnekliğinin Aracı Rolü}

Tedarik zincirinde esneklik, arzdaki bozulmaları ve talepteki ani değişmeleri tedarik zinciri yapılarına uyarlayarak müşteri hizmet düzeylerini korumak anlamına gelmektedir (Kumar vd., 2008). Tedarik zinciri esnekliği, ürün esnekliği, hacim esnekliği, yeni ürün esnekliği ve dağıtım esnekliğinin bir birleşimi olarak tanımlanmaktadır (Vickery vd., 1999).

Tedarik zinciri esnekliği, müşteriye ürün/ hizmet sunum sürecinde yaşanabilecek değişimlerin ve karşılaşılabilecek belirsizliklerin en hızlı şekilde ve en düşük maliyetle üstesinden gelebilmek amaciyla, tedarik zincirinde yer alan birimlerin faaliyetlerini, bu birimler arasındaki ilişkileri ve tedarik zinciri yapılarını düzenleyebilme becerisi olarak da tanımlanabilir. Tedarik zincirinin esnekliği, pazardaki değişimlere uyum sağlayabilmek ve zincir içerisindeki aksaklıkların sistemin çökmesine yol açmasını önleyebilmek amacıyla tedarik zinciri kuran işletmelerin sağlamaya çalıştığı bir özelliktir (Topoyan, 2011).

Tedarik zinciri esnekliği; işletmeye çevresel değişikliklere ve belirsizliklere karşı anlamlı şekilde cevap verebilme yeteneği kazandırmakta ve yüksek kalitede ürün ve hizmet geliştirmesine katkıda bulunmaktadır. Tedarik zincirindeki esneklik kavramı işletmelerin sipariș miktarlarını, teslim sürelerini ve üretim programlarını değiştirebilme yetenekleri gibi unsurları içermektedir (Çalışkan vd., 2016).

Yapılan literatür taramasında tedarik zinciri esnekliğinin, işletim sistemleri esnekliği, pazar esnekliği, lojistik esnekliği, tedarik esnekliği, organizasyonel esneklik, üretim esnekliği ve bilgi sistemleri esnekliği olarak tanımlandığı görülmüş̧ür. Ancak çalışma kapsamında sadece lojistik esnekliği, tedarik esnekliği ve üretim esnekliği ele alınmaktadır. Lojistik esnekliği, değişen çevresel koşullarına cevaben hammaddelerin, mamullerin, hizmetlerin ve menşeli varış noktasındaki ilgili bilgilerin akışını ve depolanmasını kontrol etme kabiliyeti olarak tanımlanmaktadır. Üretim esnekliği, üretim kaynaklarını, kabul edilebilir kalitede farklı ürünleri verimli bir şekilde üretecek şekilde yeniden yapılandırma yeteneği olarak tanımlanmaktadır. Tedarik (kaynak) esnekliği ise, parça başına tedarik sayısı ve teslimat programı gibi tedarik kararlarını değiştirme yeteneği şeklinde tanımlanmaktadır (Kumar vd., 2008).

Tedarik zinciri esnekliği, tedarik zinciri riskini azaltmak için kilit kollardan biri olarak kabul edilmektedir (Sreedevi ve Saranga, 2017). tedarik zincirinin esnekliğe sahip olması, belirsizlik olduğu durumlarda daha hızlı yanıt vermeyi kolaylaştırmakta, kuruluşun ürün ve hizmetlerini zamanında ve etkin bir şsekilde sunma yeteneğini geliştirmektedir (Kumar vd., 2008). Ayrıca tedarikçiler arasındaki ilişkiler tedarik esnekliğini sağlayan önemli bir unsurdur. Bunun sonucu olarak tedarikçiler arasındaki ilişkiler işletmelerin belirsiz çevre koşullarında sürekli değişen malzeme gereksinimlerine etkin bir şekilde cevap vermelerini sağlamanın yanısıra tedarikçilerin riskleri paylaşma konusundaki istekliliklerini de arttırmaktadır (Cooper \& Ellram, 1993). 


\subsection{Araştırmanin Amact}

\section{Metodoloji}

Araştırmanın amacı, işletmelerin karşı karşıya kaldıkları tedarik zinciri operasyonel riskinin önceliklerini ve bu risklerin hangi koşullarda hafifletilebileceğini anlamaktır. Bu amaç doğrultusunda çevresel belirsizlik ve tedarik zinciri riskinde tedarik zinciri esnekliğinin aracı rolü araştırılmaktadır.

4.2.Araştırmanın Yöntemi

Araştırmada veri toplama metodu olarak anket yöntemi seçilmiştir. Araştırmanın anakütlesini Erzurum ilinde faaliyet gösteren üretim işletmeleri oluşturmaktadır. $\mathrm{Bu}$ anlamda 87 adet anket formu değerlendirmeye tabi tutulmuştur.

Araştırmada kullanılan anket formu 32 sorudan oluşmaktadır. Araştırma modelindeki değişkenlere ilişkin olarak oluşturulan 25 sorudan 6 tanesi çevresel belirsizlik, 8 tanesi tedarik zinciri esnekliği, 6 tanesi tedarik zinciri riski, 3 tanesi rekabet yoğunluğu ve son olarak 2 tanesi de önleyici risk azaltmaya yönelik algılara ait sorulardır. Araştıma modeli dışında sorulan 6 soru ise cevaplayıcıların demografik özelliklerini belirlemeye yöneliktir.

4.3.Araştırmada Kullanılan Ölçekler, Model ve Hipotezler

$\mathrm{Bu}$ çalışmada literatür taraması yapıldıktan sonra amaca uygun olduğu düşünülen Sreedevi ve Saranga (2017) çalışmasındaki ölçek ve araştırma modeli kullanılmışıtır.

$\mathrm{Bu}$ çalışmada kullanılan ölçekler 5'li Likert Tipindedir. Ölçekteki değerlendirme seçenekleri: 1- Kesinlikle Katılmıyorum, 2- Katılmıyorum, 3Kararsızım, 4- Katıliyorum ve 5- Kesinlikle Katılıyorum şeklindedir.

$\mathrm{Bu}$ çalışmada kullanılan araştırma modeli Şekil 1'de verilmiştir.

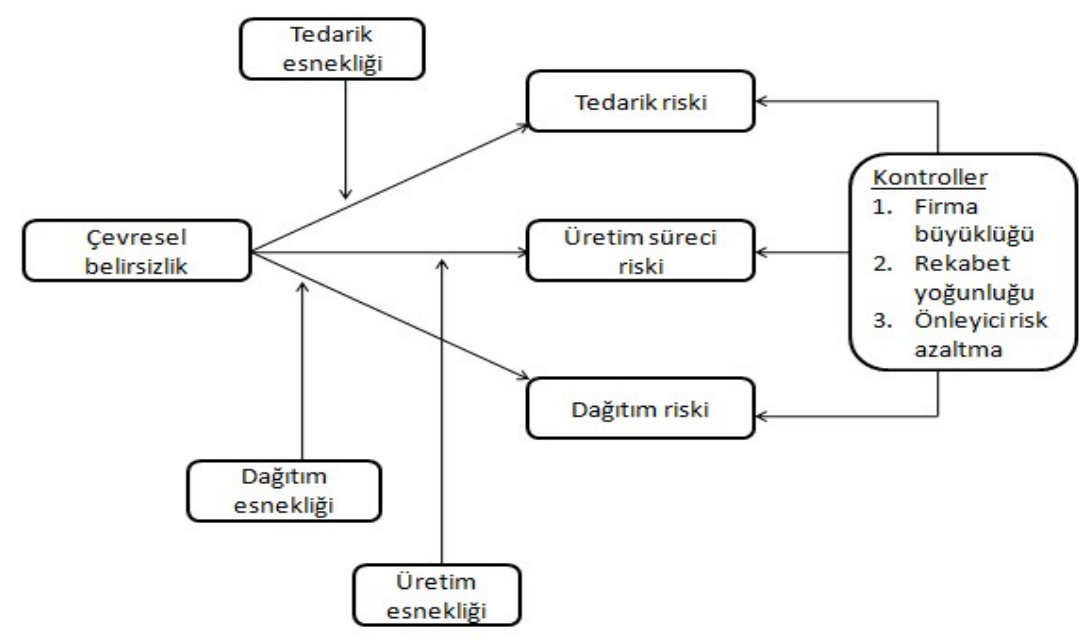

Şekil 1. Araştırma Modeli

Araştırma modeli kapsamında oluşturulan hipotezler aşağıdaki gibidir:

$\mathrm{H}_{1}$ : Çevresel belirsizlik tedarik riski üzerinde etkiye sahiptir. 
Belirsizlik ve Tedarik Zinciri Riski: Risk Azaltımında Tedarik Zinciri Esnekliğinin Aracı Rolü

$\mathrm{H}_{2}$ : Çevresel belirsizlik üretim süreci riski üzerinde etkiye sahiptir.

$\mathrm{H}_{3}$ : Çevresel belirsizlik dağıtım riski üzerinde etkiye sahiptir.

$\mathrm{H}_{4}$ : Çevresel belirsizlik ve tedarik riski arasında tedarik esnekliğinin aracılık etkisi bulunmaktadır.

$\mathrm{H}_{5}$ : Çevresel belirsizlik ve dağıtım riski arasında dağıtım esnekliğinin aracilık etkisi bulunmaktadır.

$\mathrm{H}_{6}$ : Çevresel belirsizlik ve üretim süreci riski arasında üretim esnekliğinin aracilık etkisi bulunmaktadır.

Araştırma hipotezleri, verilerin analizi ve değerlendirilmesi kısmında teste tabi tutulmuş ve sonuçlar yorumlanmıştır.

\section{Bulgular ve Tartışma}

Çalışmada Erzurum ilinde faaliyet gösteren 87 üretim işletmesinden alınan cevaplar doğrultusunda analizler yürütülmüştür. Araştırmada çevresel belirsizlik ve tedarik zinciri riskinde tedarik zinciri esnekliğinin araci rolünü araştırmak adına SPSS 23 programı kullanılarak Varyans analizi, Regresyon analizi ve Sobel $\mathrm{z}$ testi yapılmıştır. Yapılan analizler aşağıda sırasıyla açıklanmaktadır.

\subsection{Araştırmaya Katılanların Demografik Özellikleri}

Araştırmada ankete katılan cevaplayıcıların demografik özellikleri hakkında bilgi sahibi olmak adına cinsiyet, yaş, eğitim durumu, faaliyet gösterdikleri sektör, çalışan sayısı ve faaliyet süresi araştırılmış ve elde edilen bilgiler Tablo 1'de verilmiştir.

Tablo 1. Örneklem Karakteristikleri

\begin{tabular}{|c|c|c|c|c|c|}
\hline & Frekans & Yüzde & & Frekans & Yüzde \\
\hline Cinsiyet & & & Sektör & & \\
\hline Kadın & 10 & 11,5 & Mobilya & 5 & 5,7 \\
\hline \multirow{2}{*}{ Erkek } & 77 & 88,5 & Metal & 13 & 14,9 \\
\hline & & & Kimyasal-Gaz & 4 & 4,6 \\
\hline Yaş & & & G1da-Yem & 31 & 35,6 \\
\hline $20-30$ & 15 & 17,2 & Bask1-Ambalaj & 12 & 13,8 \\
\hline $31-40$ & 43 & 49,4 & Geri-Dönüşüm & 1 & 1,1 \\
\hline $41-50$ & 20 & 23,0 & Diğer..... & 21 & 24,1 \\
\hline \multirow[t]{2}{*}{$51-60$} & 9 & 10,3 & Çalışan Sayısı & & \\
\hline & & & 20 'den $\mathrm{Az}$ & 49 & 56,3 \\
\hline Eğitim Durumu & & & $20-39$ & 27 & 31,0 \\
\hline İlköğretim & 6 & 6,9 & $40-59$ & 7 & 8,0 \\
\hline Lise & 22 & 25,3 & $60 \mathrm{Ve}$ üzeri & 4 & 4,6 \\
\hline Yüksekokul & 20 & 23,0 & & & \\
\hline Üniversite & 35 & 40,2 & Faaliyet Süresi & & \\
\hline \multirow[t]{4}{*}{ Lisansüstü } & 4 & 4,6 & $1-5$ & 26 & 29,9 \\
\hline & & & $6-10$ & 20 & 23,0 \\
\hline & & & $11-15$ & 19 & 21,8 \\
\hline & & & $15+$ & 22 & 25,3 \\
\hline
\end{tabular}


Araştırmaya katılan bireyler cinsiyetleri açısından incelendiğinde, 87 kişiden oluşan örnek büyüklüğünün \%11,5'inin kadın, \%88,5'ini erkek, \%49,4'ünün 31-40 yaş grubunda olduğu görülmektedir. Bireylerin eğitim seviyesine bakıldığında ise büyük bir bölümünün $\% 40,2$ ile üniversite mezunu olduğu görülmektedir.

Üretim işletmeleri sektör açısından incelendiğinde araştırmaya katılan işletmelerden en yüksek payın \%35,6 ile gıda ve yem üreticisi olduğu görülmektedir. Yine işletmelerin \%56,3'ünün 20 'den az çalışana sahip olduğu görülmektedir. Son olarak ise araştırmaya katılan üretim işletmeleri faaliyet süreleri açısından incelendiğinde en yüksek pay ile \%29,9'luk bir kısmın 1-5 yıl süre ile faaliyet gösterdiği görülmektedir.

\section{2.Çevresel Belirsizlik ve Tedarik Riski Arasındaki İlişkide Tedarik} Zinciri Esnekliğinin Aracı Rolünün Analizine Yönelik Algllar

Çalışmada cevaplayıcıların Erzurum'da faaliyet gösteren üretim işletmelerinin belirsizlik ve tedarik zinciri riskinde tedarik esnekliğinin aracı rolüne yönelik değerlendirmeleri araştırılmıştır. Cevaplayıcıların çevresel belirsizliğe yönelik algılarının aritmetik ortalama ve standart sapma değerleri Tablo 2'de gösterilmiştir.

Tablo 2. Cevaplayıcıların Çevresel Belirsizliğe Yönelik Algıları

\begin{tabular}{|c|c|c|}
\hline Çevresel Belirsizlik & Ortalama & $\begin{array}{l}\text { Standart } \\
\text { Sapma }\end{array}$ \\
\hline Genel Ortalama & 2,94 & 1,05 \\
\hline 1. Ürünlerimize olan talep, her hafta önemli ölçüde değişir. & 3,05 & 1,27 \\
\hline $\begin{array}{l}\text { 2. Toplam üretim hacmi, haftadan haftaya önemli ölçüde } \\
\text { değisiir. }\end{array}$ & 3,02 & 1,18 \\
\hline 3. Ürettiğimiz ürün çeşidi, her hafta önemli ölçüde değişir. & 2,63 & 1,27 \\
\hline $\begin{array}{l}\text { 4. Arz edilen ürün hacmi ve çeşidi haftadan haftaya önemli } \\
\text { ölçüde değişir. }\end{array}$ & i 2,86 & 1,32 \\
\hline $\begin{array}{l}\text { 5. Üretim yapılırken, ürünlerin özellikleri üzerinde bir çok } \\
\text { değişiklik yapılmaktadır. }\end{array}$ & 3,11 & 1,43 \\
\hline $\begin{array}{l}\text { 6. Tedarikçilerimizin, tesisimize teslim ettikleri parçalar ve } \\
\text { ürün bileşenleri üzerinde siklıla değişiklik yapmaları } \\
\text { gerekmektedir. }\end{array}$ & 2,97 & 1,43 \\
\hline
\end{tabular}

Tablo 2'de görüldüğü gibi cevaplayıcıların çevresel belirsizliğe yönelik tutumlarının genel ortalamas1 2,94'tür. Cevaplayıcıların üretim yapılırken, ürünlerin özellikleri üzerinde birçok değişiklik yapılması konusundaki değerlendirmeleri 3,11 ile yüksek düzeydedir. Nispeten, çevresel belirsizlik açısından en düşük olarak değerlendirdikleri boyut ise, 2,63 ile üretilen ürün çeşidinin her hafta önemli ölçüde değişmesidir.

Cevaplayıcıların tedarik zinciri esnekliğine yönelik algılarının aritmetik ortalama ve standart sapma değerleri Tablo 3'te gösterilmiştir. 
Belirsizlik ve Tedarik Zinciri Riski: Risk Azaltımında Tedarik Zinciri Esnekliğinin Aracı Rolü

Tablo 3. Cevaplayıcıların Tedarik Zinciri Esnekliğine Yönelik Algıları

\begin{tabular}{|c|c|c|}
\hline Tedarik Esnekliği & Ortalama & $\begin{array}{l}\text { Standart } \\
\text { Sapma }\end{array}$ \\
\hline Genel Ortalama & $\mathbf{3 , 5 6}$ & 0,85 \\
\hline 7. Tedarikçilerimizin sayısı değişkenlik gösterir. & 3,69 & 1,28 \\
\hline $\begin{array}{l}\text { 8. Bizim için önem arz eden tedarikçilerimiz ile uzun } \\
\text { vadeli anlaşmalar, risk ve gelir paylaşımı gibi işbirlikçi } \\
\text { yaklaşımlar geliștirmekteyiz. }\end{array}$ & 3,60 & 1,14 \\
\hline $\begin{array}{l}\text { 9. Bizim için önem arz eden tedarikçilerimiz ile ürün } \\
\text { tasarımı, süreç tasarımı gibi konularda ortak kararlar } \\
\text { vermekteviz. }\end{array}$ & 3,39 & 1,20 \\
\hline Üretim Esnekliği & Ortalama & $\begin{array}{l}\text { Standart } \\
\text { Sapma }\end{array}$ \\
\hline Genel Ortalama & 3,06 & 1,04 \\
\hline $\begin{array}{l}\text { 10. Tedarik zincirinde } \\
\text { kapasiteden yararlanırız. }\end{array}$ & 3,11 & 1,22 \\
\hline $\begin{array}{l}\text { 11. Tedarik zincirinde riski azaltmak için fazla işgücü } \\
\text { bulundururuz. }\end{array}$ & 3,05 & 1,34 \\
\hline $\begin{array}{l}\text { 12. Tedarik zincirinde riski azaltmak için üretimde bazı } \\
\text { süreçleri talebe uygun olarak erteleriz. }\end{array}$ & 3,03 & 1,29 \\
\hline Dağıtım Esnekliği & Ortalama & $\begin{array}{l}\text { Standart } \\
\text { Sapma }\end{array}$ \\
\hline Genel Ortalama & 2,84 & 1,21 \\
\hline $\begin{array}{l}\text { 13. Tedarik zincirinde riski azaltmak için birden fazla } \\
\text { ulaşım türü ve rotası tercih ederiz. }\end{array}$ & 3,05 & 1,34 \\
\hline $\begin{array}{l}\text { 14. Uluslararası bir dağıtım stratejisi geliştirmeye } \\
\text { çalışmaktayız. }\end{array}$ & 2,66 & 1,47 \\
\hline
\end{tabular}

Tablo 3'te görüldüğü gibi cevaplayıcıların tedarik esnekliğine yönelik tutumlarının genel ortalaması 3,56'dır. Cevaplayıcıların tedarikçi sayılarının değişkenlik göstermesi konusundaki değerlendirmeleri 3,69 ile yüksek düzeydedir. Nispeten kendileri için önem arz eden tedarikçiler ile ürün tasarımı, süreç tasarımı gibi konularda ortak kararlar verilmesi yönündeki değerlendirmeleri ise 3,39 ile en düşük değere sahiptir.

Cevaplayıcıların üretim esnekliğine yönelik tutumlarının genel ortalamas 13,06'dır. Tedarik zincirinde riski azaltmak için aşırı kapasiteden yararlanılması konusundaki değerlendirmeleri 3,11 ile yüksek düzeydedir. Nispeten, tedarik zincirinde riski azaltmak için üretimde bazı süreçlerin talebe uygun olarak ertelemesi boyutundaki değerlendirmeleri ise 3,03 ile en düşük değere sahiptir. Cevaplayıcıların dağıtım esnekliğine yönelik tutumlarının genel ortalaması ise 2,84'tür. Cevaplayıcıların tedarik zincirinde riski azaltmak için birden fazla ulaşım türü ve rotası tercih edilmesine yönelik değerlendirmeleri ise 3,05 yüksek düzeyde, uluslararası bir dağıtım stratejisi geliştirilmeye çalışılması boyutundaki değerlendirmelerinin ise 2,66 ile en düşük değere sahip olduğu görülmektedir. 
Cevaplayıcıların tedarik zinciri riskine yönelik algılarının ortalama ve standart sapma değerleri Tablo 4'te verilmiştir.

Tablo 4. Cevaplayıcıların Tedarik Zinciri Riskine Yönelik Algıları

\begin{tabular}{|c|c|c|}
\hline Tedarik riski & Ortalama & $\begin{array}{l}\text { Standart } \\
\text { Sapma }\end{array}$ \\
\hline Genel Ortalama & 3,17 & 1,21 \\
\hline $\begin{array}{l}\text { 15. Bizim için önem arz eden tedarikçilerimizin, } \\
\text { faaliyetlerimizi etkileyen gerekli malzemeleri tedarik } \\
\text { edememe olasılığ } 1 \text { bulunmaktadır. }\end{array}$ & 2,89 & 1,33 \\
\hline $\begin{array}{l}\text { 16. Bizim için önem arz eden tedarikçilerimizin gerekli } \\
\text { malzemeleri tedarik edememesi bizim faaliyetlerimizi } \\
\text { etkiler. }\end{array}$ & 3,45 & 1,41 \\
\hline Üretim Riski & Ortalama & $\begin{array}{l}\text { Standart } \\
\text { Sapma }\end{array}$ \\
\hline Genel Ortalama & 3,33 & 1,29 \\
\hline $\begin{array}{l}\text { 17. Teslimatlarımızı etkileyen üretim faaliyetlerimizin } \\
\text { aksama olasılığı vardır. }\end{array}$ & 3,15 & 1,39 \\
\hline $\begin{array}{l}\text { 18. Üretim faaliyetlerimizin aksaması teslimatlarımızı } \\
\text { etkiler. }\end{array}$ & 3,52 & 1,40 \\
\hline Dağıtım Riski & Ortalama & $\begin{array}{l}\text { Standart } \\
\text { Sapma }\end{array}$ \\
\hline Genel Ortalama & 3,37 & 1,32 \\
\hline $\begin{array}{l}\text { 19. Teslimatlarımızı etkileyen sevkiyat işlemlerimizin } \\
\text { aksama olasılığı vardır. }\end{array}$ & 3,26 & 1,38 \\
\hline $\begin{array}{l}\text { 20. Sevkiyat işlemlerimizin aksaması teslimatlarımızı } \\
\text { etkiler. }\end{array}$ & 3,48 & 1,36 \\
\hline
\end{tabular}

Tablo 4'te görüldüğ̈̈ gibi cevaplayıcıların tedarik riskine yönelik tutumlarının genel ortalaması 3,17'dir. Cevaplayıcıların en yüksek değerlendirdikleri boyut 3,45 ile kendileri için önem arz eden tedarikçilerinin gerekli malzemeleri tedarik edememesi durumunda faaliyetlerinin etkilenmesidir. En düşük değerlendirdikleri boyut ise 2,89 ile kendileri için önem arz eden tedarikçilerin, faaliyetlerini etkileyen gerekli malzemeleri tedarik edememe olasılığı bulunması durumudur.

Cevaplayıcıların üretim riskine yönelik tutumlarının genel ortalaması 3,33'tür. Cevaplayıcıların üretim faaliyetlerinin aksamasının teslimatlarını etkilemesine yönelik boyutu değerlendirmeleri 3,52 ile en yüksek düzeyde, teslimatlarını etkileyen üretim faaliyetlerinin aksama olasılığının varlığına yönelik değerlendirmeleri ise 3,15 ile en düşük düzeydedir. Cevaplayıcıların dağıtım riskine yönelik tutumlarının genel ortalaması 3,37'dir. Cevaplayıcıların sevkiyat işlemlerinin aksamasının teslimatlarını etkilemesine yönelik boyutu değerlendirmeleri 3,48 ile en yüksek düzeyde, teslimatlarını etkileyen sevkiyat işlemlerinin aksama olasıllğı varlığına yönelik boyutu değerlendirmeleri ise 3,26 ile en düşük düzeydedir. 
Belirsizlik ve Tedarik Zinciri Riski: Risk Azaltımında Tedarik Zinciri Esnekliğinin Aracı Rolü

Cevaplayıcıların tedarik zinciri riski kontrollerine yönelik algılarının ortalama ve standart sapma değerleri Tablo 5 'te verilmiştir.

Tablo 5. Cevaplayıcıların Tedarik Zinciri Riski Kontrollerine Yönelik Algıları

\begin{tabular}{lll}
\hline Rekabet Yoğunluğu & Ortalama & $\begin{array}{l}\text { Standart } \\
\text { Sapma }\end{array}$ \\
\hline Genel Ortalama & $\mathbf{3 , 9 1}$ & $\mathbf{0 , 8 8}$ \\
\hline $\begin{array}{l}\text { 21. İşletmemiz yoğun bir piyasada faaliyet göstermektedir. } \\
\text { 22. Sanayide rekabete dayalı çekişme mevcuttur. }\end{array}$ & 4,05 & 1,09 \\
$\begin{array}{l}\text { 23. Faaliyette bulunduğumuz pazara giriş zordur. } \\
\text { Önleyici Risk Azaltma }\end{array}$ & 4,00 & 1,06 \\
Genel Ortalama & 3,69 & 1,20 \\
$\begin{array}{l}\text { 24. Daha güvenilir bir tedarikçi seçilmesi, açık güvenlik } \\
\text { prosedürlerinin uygulanması, önleyici bakım gibi vasıtalarla } \\
\text { faaliyetimize yönelik riskleri hafifletiriz. }\end{array}$ & 3,85 & 0,91 \\
$\begin{array}{l}\text { 25. Tedarikçilerin ve firmamızın izlenmesi, denetimi ve takip } \\
\text { edilmesi gibi vasitalarla faaliyetimize yönelik meydana } \\
\text { gelecek riskleri tespit ederiz. }\end{array}$ & & $\mathbf{3 , 9 3}$ \\
\hline
\end{tabular}

Tablo 5'te görüldüğü gibi cevaplayıcıların rekabet yoğunluğuna yönelik tutumlarının genel ortalaması 3,91'dir. Cevaplayıcıların işletmelerinin yoğun bir piyasada faaliyet gösterdiğine yönelik boyutu değerlendirmeleri 4,05 ile en yüksek düzeydedir. Cevaplayıcıların en düşük değerlendirdikleri boyut ise 3,69 ile faaliyette bulundukları pazara girişin zor olduğudur. Cevaplayıcıların önleyici risk azaltmaya yönelik tutumlarını genel ortalamas1 3,93'dir. Cevaplayıcıların en yüksek değerlendirdikleri boyut 4,01 ile tedarikçilerinin ve firmalarının izlenmesi, denetimi ve takip edilmesi gibi vasıtalarla faaliyetlerine yönelik meydana gelecek risklerin tespit edildiğidir. En düşük değerlendirdikleri boyut ise 3,85 ile daha güvenilir bir tedarikçi seçilmesi, açık güvenlik prosedürlerinin uygulanması, önleyici bakım gibi vasıtalarla faaliyetlerine yönelik risklerin hafifletilebileceğidir.

\section{3.Çevresel Belirsizlik ve Tedarik Zinciri Riski Arasındaki Iliş̧kide} Tedarik Zinciri Esnekliğinin Aracı Rolünün Analizi

Çalışmada çevresel belirsizlik ve tedarik zinciri riski arasındaki ilişkide tedarik zinciri esnekliğinin aracı rolünün analizine geçilmeden önce değişkenler üzerinde tek yönlü varyans analizi (ANOVA) uygulanmıştır.

Çevresel belirsizlik, tedarik zinciri esnekliği ve tedarik zinciri riskinin sektörlere göre anlamlı farklılık gösterip göstermediğini test etmek amacıyla tek yönlü varyans analizi yapılmış değerler Tablo 6' da verilmiştir. 
Tablo 6. Çevresel Belirsizlik, Tedarik Esnekliği ve Tedarik Riskinin Sektörlere Göre Tek Yönlü Varyans Analizi Sonuçları

\begin{tabular}{|c|c|c|c|c|c|c|}
\hline & Sektör & $\mathbf{N}$ & $\begin{array}{l}\text { Standart } \\
\text { Sapma }\end{array}$ & $\begin{array}{l}\text { Standart } \\
\text { Hata }\end{array}$ & $\mathbf{F}$ & $\mathbf{P}$ \\
\hline \multirow{8}{*}{$\begin{array}{l}\text { Çevresel } \\
\text { Belirsizlik }\end{array}$} & Mobilya & 5 & 1,23 & 0,55 & \multirow[t]{8}{*}{0,84} & \multirow[t]{8}{*}{0,54} \\
\hline & Metal & 13 & 0,98 & 0,27 & & \\
\hline & Kimyasal gaz & 4 & 1,79 & 0,90 & & \\
\hline & Gida- yem & 31 & 0,93 & 0,17 & & \\
\hline & Bask1- ambalaj & 12 & 1,25 & 0,36 & & \\
\hline & Geri dönüşüm & 1 & & & & \\
\hline & Diğer & 21 & 0,99 & 0,22 & & \\
\hline & Toplam & 87 & 1,05 & 0,11 & & \\
\hline \multicolumn{2}{|r|}{ Sektör } & $\mathbf{N}$ & $\begin{array}{l}\text { Standart } \\
\text { Sapma }\end{array}$ & $\begin{array}{l}\text { Standart } \\
\text { Hata }\end{array}$ & $\mathbf{F}$ & $\mathbf{P}$ \\
\hline \multirow{8}{*}{ Tedarik Esnekliği } & Mobilya & 5 & 1,15 & 0,51 & \multirow[t]{8}{*}{0,92} & \multirow[t]{8}{*}{0,49} \\
\hline & Metal & 13 & 0,96 & 0,27 & & \\
\hline & Kimyasal gaz & 4 & 1,42 & 0,71 & & \\
\hline & Gida- yem & 31 & 0,73 & 0,13 & & \\
\hline & Baskı- ambalaj & 12 & 0,69 & 0,20 & & \\
\hline & Geri dönüşüm & 1 & & & & \\
\hline & Diğer & 21 & 0,87 & 0,19 & & \\
\hline & Toplam & 87 & 0,86 & 0,09 & & \\
\hline \multirow{8}{*}{ Tedarik Riski } & Mobilya & 5 & 1,58 & 0,71 & \multirow[t]{8}{*}{1,86} & \multirow[t]{8}{*}{0,10} \\
\hline & Metal & 13 & 0,80 & 0,22 & & \\
\hline & Kimyasal gaz & 4 & 1,29 & 0,65 & & \\
\hline & Gida- yem & 31 & 1,24 & 0,22 & & \\
\hline & Bask1- ambalaj & 12 & 1,21 & 0,35 & & \\
\hline & Geri dönüşüm & 1 & & & & \\
\hline & Diğer & 21 & 1,15 & 0,25 & & \\
\hline & Toplam & 87 & 1,21 & 0,13 & & \\
\hline
\end{tabular}

Tablo 6'da görüldüğ̈̈ gibi çevresel belirsizlik, tedarik esnekliği ve tedarik riskinin sektörlere göre anlamlı olarak farklılaşıp farklılaşmadığını belirlemek için yapılan tek yönlü varyans analizi sonucunda sektörlere göre çevresel belirsizliğin anlamlı olarak farklılaşmadığ 1 ve sektörlerin çevresel belirsizlik üzerinde anlamlı bir etkiye sahip olmadığı sonucuna ulaşılmıştır $(\mathrm{p}>0.05)$. Diğer yandan, sektörlerin tedarik esnekliği ve tedarik riski üzerinde anlamlı bir etkiye sahip olduğu görülmüştür $(\mathrm{p}<0.05)$.

Çevresel belirsizlik, tedarik zinciri esnekliği ve tedarik zinciri riskinin faaliyet süresine göre anlamlı farklılık gösterip göstermediğini test etmek amacıyla tek yönlü varyans analizi yapılmış değerler Tablo 7'de verilmiştir. 
Belirsizlik ve Tedarik Zinciri Riski: Risk Azaltımında Tedarik Zinciri Esnekliğinin Aracı Rolü

Tablo 7. Çevresel Belirsizlik, Tedarik Esnekliği, Dağıtım Esnekliği, Tedarik Riski Ve Üretim Riskinin Faaliyet Süresine Göre Tek Yönlü Varyans Analizi Sonuçları

\begin{tabular}{|c|c|c|c|c|c|c|}
\hline \multicolumn{2}{|c|}{ Faaliyet Süresi } & \multirow{2}{*}{$\frac{\mathbf{N}}{26}$} & \multirow{2}{*}{$\begin{array}{l}\text { Standart Sapma } \\
0,98\end{array}$} & \multirow{2}{*}{$\begin{array}{l}\text { Standart Hata } \\
0,19\end{array}$} & \multirow{2}{*}{$\frac{\mathbf{F}}{1,00}$} & \multirow{2}{*}{$\frac{\mathbf{P}}{0,40}$} \\
\hline \multirow{5}{*}{ Çevresel Belirsizlik } & $1-5$ & & & & & \\
\hline & $6-10$ & 20 & 1,21 & 0,27 & & \\
\hline & $11-15$ & 19 & 1,11 & 0,25 & & \\
\hline & $15+$ & 22 & ,93 & 0,20 & & \\
\hline & Toplam & 87 & 1,05 & 0,11 & & \\
\hline \multirow{5}{*}{ Tedarik Esnekliği } & $1-5$ & 26 & 0,75 & 0,15 & 0,34 & 0,80 \\
\hline & $6-10$ & 20 & 0,97 & 0,22 & & \\
\hline & $11-15$ & 19 & 1,11 & 0,26 & & \\
\hline & $15+$ & 22 & 0,61 & 0,13 & & \\
\hline & Toplam & 87 & 0,86 & 0,09 & & \\
\hline \multirow{5}{*}{ Dağıtım Esnekliği } & $1-5$ & 25 & 1,43 & 0,29 & 0,36 & 0,79 \\
\hline & $6-10$ & 20 & 1,15 & 0,26 & & \\
\hline & $11-15$ & 19 & 1,05 & 0,24 & & \\
\hline & $15+$ & 22 & 1,17 & 0,25 & & \\
\hline & Toplam & 86 & 1,21 & 0,13 & & \\
\hline \multirow{5}{*}{ Tedarik Riski } & $1-5$ & 26 & 1,16 & 0,23 & 2,60 & 0,06 \\
\hline & $6-10$ & 20 & 1,28 & 0,29 & & \\
\hline & $11-15$ & 19 & 1,21 & 0,28 & & \\
\hline & $15+$ & 22 & 1,09 & 0,23 & & \\
\hline & Toplam & 87 & 1,21 & 0,13 & & \\
\hline \multirow{5}{*}{ Üretim Riski } & $1-5$ & 26 & 1,12 & 0,22 & 1,94 & 0,13 \\
\hline & $6-10$ & 20 & 1,54 & 0,35 & & \\
\hline & $11-15$ & 19 & 1,33 & 0,30 & & \\
\hline & $15+$ & 22 & 1,13 & 0,24 & & \\
\hline & Toplam & 87 & 1,30 & 0,14 & & \\
\hline
\end{tabular}

Tablo 7'de görüldüğü gibi tek yönlü varyans analizi sonuçları incelendiğinde faaliyet süresine göre çevresel belirsizlik, tedarik esnekliği, dağıtım esnekliği, tedarik riski ve üretim riskinin anlamlı olarak farklılaşmadığı ve faaliyet süresinin bu değişkenler üzerinde anlamlı bir etkiye sahip olmadığı sonucuna ulaşılmıştır ( $\mathrm{p}>0.05)$.

Çevresel belirsizlik ve tedarik zinciri riski arasındaki ilişkinin incelenmesi amacıyla veriler regresyon analizine tabi tutulmuş ardından tedarik zinciri esnekliğinin aracı rolünü tespit etmek amaciyla sobel $\mathrm{z}$ testi uygulanmıştır. Çevresel belirsizliğin tedarik riski üzerine etkisini test etmek amacıyla regresyon analizi yapılmış değerler Tablo 8'de verilmiştir. 
Tablo 8. Çevresel Belirsizliğin Tedarik Riski Üzerine Etkisi

\begin{tabular}{lccllc}
\hline Değișkenler & \multicolumn{2}{c}{ Tedarik Riski } & \multicolumn{3}{c}{ Çoklu Doğrusallık İstatistikleri } \\
\hline $\begin{array}{l}\text { Çevresel } \\
\text { Belirsizlik }\end{array}$ & Beta & $\mathrm{t}$ & $\begin{array}{l}\text { p- } \\
\text { değeri }\end{array}$ & Tolerance & VIF \\
\cline { 2 - 6 } & $-0,24$ & $-2,27$ & 0,03 & 1,00 & 1,00 \\
$\mathbf{R}$ & 0,24 & & & & \\
$\mathbf{R}^{\mathbf{2}}$ & 0,06 & & & & \\
Düzeltilmiș $\mathbf{R}^{\mathbf{2}}$ & 0,05 & & & & \\
\hline
\end{tabular}

Tablo 8'de görüldüğü gibi oluşturulan regresyon modeli 0.05 önem düzeyinde istatistiki açıdan anlamlıdır ve $\mathrm{R}^{2}$ değeri 0.06 olarak bulunmuştur. Modelde yer alan çevresel belirsizlik, tedarik riski üzerinde etkiye sahiptir ( $\beta=$ 0.24: $\mathrm{p}<0.05$ ). Bu sonuçlar doğrultusunda $\mathrm{H}_{1}$ hipotezi kabul edilmiştir.

Çevresel belirsizliğin üretim süreci riski üzerine etkisini test etmek amacıyla regresyon analizi yapılmış değerler Tablo 9' da verilmiştir.

Tablo 9. Çevresel Belirsizliğin Üretim Süreci Riski Üzerine Etkisi

\begin{tabular}{llllll}
\hline Değişkenler & \multicolumn{2}{l}{ Üretim Süreci Riski } & \multicolumn{2}{l}{ Coklu Doğrusallık İstatistikleri } \\
\hline Çevresel & Beta & $\mathrm{t}$ & $\mathrm{p}$-değeri & Tolerance & VIF \\
\cline { 2 - 6 } Belirsizlik & $-0,17$ & $-1,63$ & 0,11 & 1,00 & 1,00 \\
$\mathbf{R}$ & 0,17 & & & & \\
$\mathbf{R}^{2}$ & 0,03 & & & & \\
Düzeltilmiş & 0,02 & & & & \\
$\mathbf{R}^{2}$ & & & & & \\
\hline
\end{tabular}

Tablo 9'da görüldüğü gibi oluşturulan regresyon modeli 0.05 önem düzeyinde istatistiki açıdan anlamlı değildir ve $\mathrm{R}^{2}$ değeri 0.03 olarak bulunmuştur. Modelde yer alan çevresel belirsizliğin, üretim süreci riski üzerinde etkiye sahip olmadığı görülmektedir $(\beta=-0.17$ : $p>0.05)$. Bu sonuçlar doğrultusunda $\mathrm{H}_{2}$ hipotezi reddedilmiştir.

Çevresel belirsizliğin dağıtım riski üzerine etkisini test etmek amacıyla regresyon analizi yapılmış değerler Tablo 10 'da verilmiştir.

Tablo 10. Çevresel Belirsizliğin Dağıtım Riski Üzerine Etkisi

\begin{tabular}{llllll}
\hline Değiskenler & \multicolumn{2}{c}{ Dağıtım Riski } & \multicolumn{3}{c}{ Çoklu Doğrusallık İstatistikleri } \\
\hline Çevresel Belirsizlik & Beta & $\mathrm{t}$ & $\mathrm{p}$-değeri & Tolerance & VIF \\
\cline { 2 - 6 } & - & - & 0,04 & 1,00 & 1,00 \\
$\mathbf{R}$ & 0,21 & 2,00 & & & \\
$\mathbf{R}^{2}$ & 0,21 & & & & \\
Düzeltilmiş $\mathbf{R}^{2}$ & 0,04 & & & & \\
\hline
\end{tabular}



Rolü

Tablo 10'da görüldüğü gibi oluşturulan regresyon modeli 0.05 önem düzeyinde istatistiki açıdan anlamlıdır ve $\mathrm{R}^{2}$ değeri 0.04 olarak bulunmuştur. Modelde yer alan çevresel belirsizliğin, dağıtım riski üzerinde etkiye sahip olduğu görülmektedir $(\beta=-0.21: \quad p<0.05)$. Bu sonuçlar doğrultusunda $\mathrm{H}_{3}$ hipotezi kabul edilmiştir.

Tedarik esnekliğinin aracı rolünü test etmek amacıyla sobel $\mathrm{z}$ testi yapılmış değerler Tablo 11'de verilmiştir.

Tablo 11. Tedarik Esnekliğinin Aracı Rolü

\begin{tabular}{lllllll}
\hline $\begin{array}{l}\text { Tedarik } \\
\begin{array}{l}\text { Esnekliğinin } \\
\text { Aracı Olduğu } \\
\text { İlişki }\end{array}\end{array}$ & $\begin{array}{l}\text { Toplam } \\
\text { Etki }\end{array}$ & $\begin{array}{l}\text { Doğrudan } \\
\text { Etki }\end{array}$ & $\begin{array}{l}\text { Dolaylı } \\
\text { Etki }\end{array}$ & $\begin{array}{l}\text { Bootstrap } \\
\text { Güven Aralığı } \\
\text { BoLLCI- } \\
\text { BoULCI }\end{array}$ & $\begin{array}{l}\text { P } \\
\text { Değeri }\end{array}$ & $\begin{array}{l}\text { Sobel Z } \\
\text { Değeri }\end{array}$ \\
\hline $\begin{array}{l}\text { Çevresel } \\
\begin{array}{l}\text { Belirsizlik- } \\
\text { Tedarik Riski }\end{array}\end{array}$ & $-0,27$ & $-0,23$ & $-0,05$ & $-0,19-0,02$ & 0,31 & $-1,01$ \\
\hline
\end{tabular}

Tablo 11'de görüldüğü gibi tedarik esnekliğinin arac1lık etkisinin anlamlılığını araştırmak için yapılan sobel z testi etki değerlerine bakıldığında toplam etkisinin $-0,27$ olduğu, doğrudan etkisinin $-0,23$ olduğu ve dolaylı etkisinin $-0,05$ olduğu görülmektedir. Bootstrap güven aralığı sonuçlarının alt ve üst sınırına bakıldı̆̆ında çevresel belirsizlik ile tedarik riski arasındaki ilişkide tedarik esnekliğinin aracı etkisinin 0.05 önem düzeyinde anlamlı olmadığı ve aracı etkiye sahip olmadığ 1 tespit edilmiştir $(\mathrm{p}>0.05)$. Bu sonuçlar doğrultusunda $\mathrm{H}_{4}$ hipotezi reddedilmiştir.

Dağıtım esnekliğinin aracı rolünü rolünü test etmek amacıyla sobel z testi yapılmış değerler Tablo 12'de verilmiştir.

Tablo 12. Dağıtım Esnekliğinin Aracı Rolü

\begin{tabular}{|l|l|l|l|l|l|c|}
\hline $\begin{array}{l}\text { Dağıtım } \\
\text { Esnekliğinin } \\
\text { Aracı Olduğu } \\
\text { İlişki }\end{array}$ & $\begin{array}{l}\text { Toplam } \\
\text { Etki }\end{array}$ & $\begin{array}{l}\text { Doğrudan } \\
\text { Etki }\end{array}$ & $\begin{array}{l}\text { Dolaylı } \\
\text { Etki }\end{array}$ & $\begin{array}{l}\text { Bootstrap } \\
\text { Güven Aralı̆̆ } \\
\text { BoLLCI- } \\
\text { BoULCI }\end{array}$ & $\begin{array}{l}\text { P } \\
\text { Değeri }\end{array}$ & $\begin{array}{l}\text { Sobel Z } \\
\text { Değeri }\end{array}$ \\
\hline $\begin{array}{l}\text { Çevresel } \\
\text { Belirsizlik- } \\
\text { Dağıtım Riski }\end{array}$ & $-0,27$ & $-0,31$ & 0,04 & $-0,03-0,15$ & 0,40 & 0,84 \\
\hline
\end{tabular}

Tablo 12'de görüldüğü gibi dağıtım esnekliğinin aracılık etkisinin anlamlılığına yönelik etki değerlerine bakıldığında toplam etkisinin $-0,27$ olduğu, doğrudan etkisinin $-0,31$ olduğu ve dolaylı etkisinin 0,04 olduğu görülmektedir. Bootstrap güven aralığı sonuçlarının alt ve üst sınırına bakıldığında çevresel belirsizlik ile dağıtım riski arasındaki ilişkide dağıtım esnekliğinin aracı etkisinin 0.05 önem düzeyinde anlamlı olmadığı ve aracı etkiye sahip olmadığ tespit edilmiştir $(\mathrm{p}>0.05)$. Bu sonuçlar doğrultusunda $\mathrm{H}_{5}$ hipotezi reddedilmiştir.

Üretim esnekliğinin aracı rolünü test etmek amaciyla sobel $\mathrm{z}$ testi yapılmış değerler Tablo 13’te verilmiştir. 
Tablo 13. Üretim Esnekliğinin Aracı Rolü

\begin{tabular}{lllllll}
\hline $\begin{array}{l}\text { Üretim } \\
\text { Esnekliğinin } \\
\begin{array}{l}\text { Aracı Olduğu Etki } \\
\text { İlişki }\end{array}\end{array}$ & $\begin{array}{l}\text { Toplam } \\
\text { Doğrudan }\end{array}$ & $\begin{array}{l}\text { Dolaylı } \\
\text { Etki }\end{array}$ & $\begin{array}{l}\text { Bootstrap } \\
\text { Aralığı } \\
\text { BoULCI }\end{array}$ & $\begin{array}{c}\text { Güven } \\
\text { BoLLCI- }\end{array}$ & $\begin{array}{l}\text { Sobel Z } \\
\text { Değeri }\end{array}$ & $\begin{array}{l}\text { Değeri } \\
\text { Detki }\end{array}$ \\
\hline $\begin{array}{l}\text { Çevresel } \\
\begin{array}{l}\text { Belirsizlik Üretim } \\
\text { Süreci Riski }\end{array}\end{array}$ & $-0,22$ & $-0,22$ & $-0,00$ & $-0,10-0,07$ & 0,96 & $-0,05$ \\
\hline
\end{tabular}

Tablo 13'te görüldüğü gibi üretim esnekliğinin aracıllk etkisinin anlamlılığına yönelik etki değerlerine bakıldığında toplam etkisinin $-0,22$ olduğu, doğrudan etkisinin $-0,22$ olduğu ve dolaylı etkisinin $-0,00$ olduğu görülmektedir. Bootstrap güven aralığı sonuçlarının alt ve üst sınırına bakıldığında çevresel belirsizlik ile üretim süreci riski arasındaki ilişkide üretim esnekliğinin aracı etkisinin 0.05 önem düzeyinde anlamlı olmadığı ve aracı etkiye sahip olmadığı tespit edilmiştir ( $p>0.05)$. Bu sonuçlar doğrultusunda $\mathrm{H}_{6}$ hipotezi reddedilmiştir.

Araştırma modeli kapsamında oluşturulan ve analiz edilen hipotez sonuçları Tablo 14'te verilmiştir.

Tablo 14. Hipotez Sonuçları

\begin{tabular}{lll}
\hline Hipotez & p-değeri & Karar \\
\hline $\mathrm{H}_{1}$ & $\mathrm{P}<0.05$ & Kabul \\
\hline $\mathrm{H}_{2}$ & $\mathrm{P}>0.05$ & Red \\
\hline $\mathrm{H}_{3}$ & $\mathrm{P}<0.05$ & Kabul \\
\hline $\mathrm{H}_{4}$ & $\mathrm{P}>0.05$ & Red \\
\hline $\mathrm{H}_{5}$ & $\mathrm{P}>0.05$ & Red \\
\hline $\mathrm{H}_{6}$ & $\mathrm{P}>0.05$ & Red \\
\hline
\end{tabular}

Tablo 14 incelendiğinde araştırma için oluşturulan 6 hipotezden 2 tanesinin kabul edildiği, 4 tanesinin reddedildiği görülmektedir. Araştırma sonuçları doğrultusunda çevresel belirsizliğin tedarik riski ve dağıtım riski üzerinde etkiye sahip olduğu görülmektedir. Ancak çevresel belirsizliğin üretim süreci riski üzerinde etkisinin olmadığg görülmekte ve tedarik esnekliği, dağıtım esnekliği ve üretim esnekliğinin tedarik zinciri riskleri ve çevresel belirsizlik arasındaki ilişkide etkisinin olmadığı sonucuna ulaşılmaktadır.

\section{Sonuc}

$\mathrm{Bu}$ çalışmanın amacı, işletmelerin karşı karşıya kaldıkları tedarik zinciri risklerinin önceliklerini ve bu risklerin hangi koşullarda hafifletilebileceğini incelemek ve bu amaç doğrultusunda çevresel belirsizlik ve tedarik zinciri riski arasındaki ilişkide tedarik zinciri esnekliğinin aracı rolünü araştırmaktır.

Erzurum'da faaliyet gösteren üretim işletmelerine yönelik yapılan araştırma için oluşturulan 6 hipotezden 2 tanesinin kabul edildiği, 4 tanesinin 

Rolü

reddedildiği görülmektedir. Araştırma sonuçları doğrultusunda model incelendiğinde çevresel belirsizliğin tedarik riski ve dağıtım riski üzerinde etkiye sahip olduğu görülürken çevresel belirsizliğin üretim süreci riski üzerinde etkisinin olmadığı görülmektedir. Ayrıca tedarik esnekliği, dağıtım esnekliği ve üretim esnekliğinin tedarik zinciri riskleri ve çevresel belirsizlik arasındaki ilişkide etkisinin olmadığı sonucuna da ulaşılmaktadır.

Araştırmadan elde edilen veriler doğrultusunda üretim işletmelerinde çevresel belirsizlik ve tedarik riski arasındaki ilişkide tedarik zinciri esnekliğinin aracı rolünün analizine yönelik alg1 değerlerine bakıldığında, dağıtım esnekliğine yönelik algıların 2,84 ile en düşük düzeyde, önleyici risk azaltmaya yönelik algıların ise 3,93 ile en yüksek düzeyde olduğu görülmektedir.

Çevresel belirsizlik ve tedarik riski arasındaki ilişkide tedarik zinciri esnekliğinin aracı rolünü araştıran Sreedevi ve Saranga (2017) çalışmalarında, tedarik esnekliği ve üretim esnekliğinin bu ilişkide aracı bir etkiye sahip olduğunu ancak dağıtım esnekliğinin herhangi bir etkiye sahip olmadığı sonucuna ulaşılmıştır. Çalışmamızda ise, tedarik esnekliği, üretim esnekliği ve dağıtım esnekliğinin çevresel belirsizlik ve tedarik zinciri arasında aracı bir etkiye sahip olmadığ 1 sonucuna ulaşılmıştır.

Araştırma sonucunda Erzurum ilinde faaliyet gösteren ve çalışmaya katılan üretim işletmelerinin çevresel belirsizlik durumunda yapacakları faaliyetlere yönelik tedarik sağlama ve dağıtım yapma konusunda risklerle karşı karşıya kaldıkları görülmektedir. Araştırmaya katılan işletmelerin çevresel belirsizlik durumunda kendileri için önem arz eden tedarikçilerinin gerekli malzemeleri istenilen zamanda, kalitede ve miktarda tedarik edememesi nedeniyle işletme faaliyetleri aksamakta ve üretimden başlayarak müşteriye uzanan bu süreçte birçok risk ortaya çıkmaktadır. Ayrıca işletmelerin sevkiyat işlemlerinin aksaması teslimatları etkilemekte ve dolayısı ile bu aksaklıklara neden olabilecek çevresel belirsizlik koşullarının etkisini azaltabilmek adına risklere karşı öngörüye sahip olmaları gerekmektedir.

Çevresel belirsizlik durumunda tedarik riskinin artması sadece işletme içi performans1 ve kaliteyi etkilemekle kalmayıp aynı zamanda itibar kayb1, teslimat aksamaları gibi işletmenin imajını etkileyen olumsuz sonuçlar doğurmaktadır. $\mathrm{Bu}$ doğrultuda işletmelerin çevresel belirsizlik durumunda tedarik ve dağıtım risklerinden etkilenmelerini en aza indirecek stratejiler belirlemeleri ve tedarik riskine karşı güvenlik stoğu bulundurmak ve tedarik zinciri risk yönetimini etkin bir şekilde sağlamak gibi önlemler almaları gerekmektedir.

Doğru ürünün doğru zamanda müşteriye teslim edilmesi işletme açısından önemli bir başarı kriteri olmaktadır. Ancak piyasalardaki belirsizlikten kaynaklı olarak ortaya çıkan dağıtım riskinde karşılaşılan aksaklıklar teslimat başarısızlıklarına neden olmaktadır. Dolayısıyla işletmelerin ortaya çıkabilecek dağıtım risklerini en aza indirebilmek adına çevresel 
belirsizlik koşullarını öngörerek öncelikle arz riskini azaltmaya odaklanmaları gerekmektedir.

\section{Kaynaklar}

Chopra, S., Sodhi, M.S., (2004). Managing Risk To Avoid Supply-Chain Breakdown, MIT Sloan Management Review, 46 (1), 53.

Cooper, M.C., Ellram, L.M. (1993). Characteristics Of Supply Chain Management And The Implications For Purchasing And Logistics Strategy, The International Journal Of Logistics Management, 4 (2), 13 24.

Çalışkan, A., Karacasulu, M. T., Öztürkoğlu, Y. (2016). Hızlı Moda Markalarında Çevik Ve Esnek Tedarik Zinciri Yönetimi, Manisa Celal Bayar Üniversitesi Sosyal Bilimler Dergisi, 14(4), 49-74.

Çetindaş, A., Çelik, M. (2017). İmalat İşletmelerinin Tedarikçi Entegrasyonları İle Lojistik Performansları Arasındaki İlişki Üzerine Çevresel Belirsizliğin Düzenleyici Rolü, Toros Üniversitesi Sosyal Bilimler Dergisi, 4(7), 132-146.

Erciş, A., Deligoz, K. \& Gul B. (2019). Yeșil Pazarlama Faaliyetlerinin Tüketici Satın Alma Davranışına Etkileri: Erzurum İli Örneği, Journal of Academic Value Studies, Vol:5 Issue: 5, 942-956.

Erdal, H. (2017). Tarihsel Tecrübeler Işıı̆ında Tedarik Zinciri Risk Yönetiminin Önemi, Erciyes Üniversitesi İktisadi Ve İdari Bilimler Fakültesi Dergisi, 50, 121-139.

Estevez, V.Y., Rodriguez, J. R. O., Perez, A. M. G. (2010). Perceived Environmental Uncertainty In The Agrifood Supply Chain, British Food Journal, 112 (7), 688-709.

Güzel, D., Demirdöğen, O. (2016). Tedarik Zinciri Bütünleşmesi, Yeşil Tedarik Zinciri Uygulamaları ve İşletme Performansı Arasındaki İlişki Üzerine Bir Araştırma, Karabük Üniversitesi Sosyal Bilimler Enstitüsü Dergisi, $6(2), 362$.

Ho, C.F., Tai, Y.M., Chi, Y.P. (2005). A Structural Approach To Measuring Uncertainty İ̀ Supply Chains, Int. J. Electron. Commer., 9 (3), 91-114.

Jangga, R., Ali, N. M., Ismail, M., Sahari, N. (2015). Effect Of Environmental Uncertainty And Supply Chain Flexibility Towards Supply Chain Innovation: An Exploratory Study, Procedia Economics And Finance, $31,262-268$.

Kara, M. E., Fırat, S. Ü. (2015). "Tedarik Zinciri Risk Yönetiminin Gelişmesini Tetikleyen Risk Olayları Üzerine Bir İnceleme”, Ulusal Lojistik Ve Tedarik Zinciri Kongresi, 326-334.

Kumar, P., Shankar, R., Yadav, S. S. (2008). Flexibility In Global Supply Chain: Modeling The Enablers, Journal Of Modelling In Management, 3 (3), 277-297. 
Kumar, S.K., Tiwari, M.K., Babiceanu, R. F., (2010). Minimisation Of Supply Chain Cost With Embedded Risk Using Computational Intelligence Approaches. Int. J. Prod. Res., 48(13), 3717-3739.

Mital, M., Giudice, M. D., Papa, A. (2018). Comparing Supply Chain Risks For Multiple Product Categories With Cognitive Mapping And Analytic Hierarchy Process, Technological Forecasting \& Social Change, 131, 159-170.

Oliveira, U. R., Marins, F. A. S., Rocha, H. M., Salomon, V. A. P. (2017). The ISO 31000 Standard In Supply Chain Risk Management, Journal of Cleaner Production, 151, 616-633.

Sreedevi, R., Saranga, H. (2017). Uncertainty And Supply Chain Risk: The Moderating Role Of Supply Chain Flexibility In Risk Mitigation, International Journal Of Production Economics, 193, 332-342.

Srinivasan, M., Mukherjee, D., Gaur, A. S. (2011). Buyer-Supplier Partnership Quality And Supply Chain Performance: Moderating Role Of Risks, And Environmental Uncertainty, European Management Journal, 29, 260 271.

Topoyan, M. (2011). Tedarik Zinciri Esnekliğine Yönelik Bütünleşik Bir Ölçüm Modeli, Ege Akademik Bakış, 11(4), 511-523.

Vatansever, K. (2010). Tedarik Zinciri Esnekliğinin Firma Performans1 Üzerindeki Etkileri Ve Tekstil Sektöründe Bir Araştırma, Dumlupınar Üniversitesi Sosyal Bilimler Enstitüsü, Doktora Tezi, Kütahya.

Vickery, S.N., Calantone, R., Droge, C., (1999). Supply Chain Flexibility: An Empirical Study, The Journal Of Supply Chain Management, 35(3), 1624. 